\title{
Os clíticos en galego-portugués: natureza e categorización desde unha perspectiva xerativista
}

\author{
Xavier Frías-Conde \\ Ces Don Bosco (UCM / Círculo Lingüístico de Praga
}

\section{Xustificación}

O movemento pre-verbal e post-verbal en galego-portugués, e tamén en leonés, é unha das cuestións máis interesantes de analizar no eido da Romanística que, desde hai décadas, xa ten feito correr ríos de tinta. Nesta ocasión, non pretendemos desbotar ou refusar calquera teoría ao respecto, senón simplemente enfocar a cuestión desde unha perspectiva un chisco diferente das habituais, a da gramática xerativa, fornecendo unha visión diferente para a interpretación do movemento dos clíticos segundo os postulados xerativistas, aínda que nesta ocasión só estudaremos o fenómeno no relativo ao verbo simple, é dicir, non nos ocuparemos de tempos compostos ou de perífrases verbais.

Cumprirá comezarmos con dúas cuestións previas sen as cales é imposíbel entender as formulacións que aparecerán a seguir. En primeiro lugar, debemos reparar a concordancia de obxecto $(\mathrm{CO})$ como elemento clave. $\mathrm{Xa}$ nun estudo de noso anterior (Frías-Conde: 2003) introducimos a cuestión de os clíticos seren núcleos dos sintagmas de concordancia de obxecto $(\mathrm{SCO})$, asemade que a súa presenza non anula a presenza dun verdadeiro obxecto manifestado como explícito. Os núcleos dos sintagmas de obxecto son os clíticos, polo que se torna en absolutamente necesario facer unha distinción de tipo morfosintáctico, ou categorial se se prefire, entre clíticos e pronomes persoais obxecto, que será a nosa segunda cuestión clave antes de nos aventarmos ao estudo do movemento dos clíticos segundo a teoría da X-barra. Comezaremos, porén, pola segunda cuestión, a da natureza dos clíticos.

\section{Sobre a natureza dos clíticos}

En todas as linguas románicas pode facerse unha distinción moi clara entre clíticos e pronomes persoais, sen que os primeiros sexan contemplados como a variante feble dos segundos. Así, por exemplo, tradicionalmente a forma me foi considerada a variante feble (átona) de min (tónica), mais isto non explica por 
que ambas as formas poden coexistir en galego e nas máis das linguas románicas na mesma oración:

1. O teu irmán visitoume a min.

De feito, en todo o iberorrománico a presenza do clítico é obrigatoria nestes casos:

2. O teu irmão visitou-me a mim (pt)

3. Tu hermano me visitó a mí (es)

4. El teu germà em va visitar a mi (ct)

Todos estes exemplos son abondo enfáticos pola presenza tanto do clítico como do pronome, pero non son exclusivos do iberorrománico. En italiano escrito non é admisíbel, mais si o é en italiano falado, como se ve no seguinte exemplo:

5. A me mi piace la birra.

O sardo, en troques, segue ao cento por cento as tendencias iberorrománicas de dupla marca. Os exemplos anteriores resultan en sardo:

\section{Frade tuo m'at bisitadu a mie.}

Podemos considerar, xa que logo, que a presenza do pronome persoal resulta unha forma marcada, mentres que a súa ausencia sería non marcada, como sucede cos casos de suxeito explícito ${ }^{1}$. Ora ben, unha oración como (7), como debe ser interpretada atendendo á forma implícita do obxecto?

7. O teu irmán visitoume.

En principio non debería ser un problema, bastaría interpretar o trazo implícito como pro, do mesmo xeito que se fai co suxeito. Desta maneira, do mesmo modo que se fala de suxeitos omitidos (termo tradicional que equivale ao xerativista "suxeito implícito»), podemos falar de obxectos omitidos (é dicir, «obxectos implícitos», mais non categorías baleiras). Desta maneira, marcámolos tamén coa etiqueta pro. Daquela, reescribimos o exemplo (7) en (8) segundo esta interpretación:

8. O teu irmán visitoume pro.

1 Efectivamente, obsérvese como é non marcado o seguinte exemplo:

- Non veu

Mentres que si o é o segundo:

- El non veu 
Tamén é posíbel nas linguas románicas atopar dous pro na mesma oración, correspondéndose o primeiro ao suxeito e o segundo ao obxecto. En tal caso, o clítico tórnase un marcador necesario:

\section{9. pro visitoume pro.}

Quédanos, por tanto, definir que é un clítico e que o fai diferente dun pronome persoal. Para comezarmos, todas as linguas románicas distinguen un paradigma de clíticos (formas átonas) distinto do paradigma de pronomes persoais obxecto (formas tónicas). Mesmo algúns falares románicos teñen un paradigma de clíticos de suxeito distinto dos pronomes persoais de suxeito, como é o caso do friulano e os falares do norte da Italia (Frías-Conde: 2003), coñecidos como funtores.

Cinguíndonos ao galego, os paradigmas preséntanse asî:

\begin{tabular}{|c|c|c|c|c|c|c|c|}
\hline \multicolumn{5}{|c|}{ Pronomes persoais } & & \multirow{2}{*}{\multicolumn{2}{|c|}{ Clíticos }} \\
\hline nominativo & \multicolumn{4}{|c|}{ oblicuo } & & & \\
\hline$e u$ & \multicolumn{2}{|c|}{$\min$} & \multicolumn{2}{|c|}{ comigo } & \multicolumn{3}{|c|}{ me } \\
\hline$t i$ & \multicolumn{2}{|c|}{$t i$} & \multicolumn{2}{|c|}{ contigo } & & & he \\
\hline el & el & si & el & consigo & $o$ & He & se \\
\hline ela & ela & si & ela & consigo & $a$ & lle & se \\
\hline nós & \multicolumn{2}{|c|}{ nós } & \multicolumn{2}{|c|}{ (connosco) } & \multicolumn{3}{|c|}{ nos } \\
\hline vós & \multicolumn{2}{|c|}{ vós } & \multicolumn{2}{|c|}{$($ convosco) } & \multicolumn{3}{|c|}{ vos } \\
\hline eles & eles & si & eles & consigo & $o s$ & lles & se \\
\hline elas & elas & si & elas & consigo & as & lles & se \\
\hline
\end{tabular}

2 Como xa quedou dito, o duplo paradigma existe en todas as linguas románicas, sendo menos preciso nalgúns casos nas formas de plural, aínda que si se mantén mesmo aí a diferenza entre tónico e átono. Convén observar que os clíticos non existen como tales en inglés ou alemán, pois nestas linguas son só pronomes persoais no sentido máis clásico, aínda que os pronomes obxecto moi decote sexan átonos. Con todo, en alemán comeza a se desenvolver unha diferenza interesante entre pronomes obxecto tónicos e átonos, como se ve nestes exemplos:

- 'Mir 'sagtet er, dass... [enfática, co pronome obxecto tónico]

- Er sagtet mir, dass... [normal, co pronome obxecto feble]

Doutra banda, as linguas eslavas si teñen clíticos,os cales se distinguen, amais de polo trazo $[+$ tónico] [-tónico] por un sistema de énclise e próclise que ten algo que ver co galego-portugués, ao menos en checo e eslovaco. Compárese o checo:

- Líbí se mi ten film (=gústame ese filme)

- Ten film se mi líbi (=ese filme gústame)

- Mne se líbi ten film (=a min gústame ese filme)

Nos exemplos anteriores, mi é un clítico, mentres que mne é un pronome. En calquera caso, o checo non admite a dupla marca de caso, é dicir, a coexistencia do clítico co pronome persoal. 
Como é ben sabido, os pronomes persoais oblicuos ou obxecto sempre van precedidos de preposición. Os clíticos, en troques, van unidos ao verbo e non admiten mudanzas de posición dentro da oración, agás a énclise e a próclise.

Sobre da natureza dos pronomes non cómpre dicir nada novo. Ora ben, se os clíticos non son exactamente pronomes persoais, o que son?

Atendendo para o feito de seren núcleos dos sintagmas de concordancia de obxecto, han ter por forza unha natureza verbal. Aínda que historicamente derivan dos pronomes, e até podemos afirmar que algunha característica pronominal aínda se encontra neles, o certo é que os clíticos sufriron nas linguas románicas unha evolución que os levou de seren formas pronominais átonas até se tornaren nunha «especie» de morfemas verbais. Pero, que «especie» de morfemas verbais?

\section{Cara a unha nova categorización dos morfemas}

As características tan especiais dos clíticos, que funcionan como satélites arredor do verbo, obrígannos a ampliar a clasificación tradicional dos morfemas entre libres e ligados. Os clíticos non responden a ningunha destas dúas categorias, senón que máis ben parecen ser unha categoría mixta, con trazos da unha e da outra. Por iso, propomos seren denominados morfemas flotantes. O termo «flotante» define a posibilidade dos clíticos de se abalaren diante e detrás do verbo ${ }^{3}$, en cada lingua segundo unha serie de regras que non imos expor aquí.

Por tanto, se son morfemas verbais, como poden ser categorizados os clíticos? En principio, cómpre situalos nunha categoría igual ao resto de morfemas verbais que indican concordancia de persoa e de tempo ${ }^{4}$. Entendemos, xa que logo, que os verbos poden reflectir a concordancia de obxecto sempre que a presenza dun obxecto responda á súa natureza semántica, é dicir, que sexa unha cuestión valencial.

Vexamos, por exemplo, o seguinte caso:

10. Recoñecereite.

Os elementos que configuran a concordancia de suxeito (CS), o tempo (T) e a concordancia de obxecto (CO) - atendendo para o feito de o verbo ser transitivo e rexer un complemento-, vén representado así:

3 Tamén en español os clíticos teñen certo movemento. Obsérvese como co infinitivo e o xerundio, o clítico vai sempre enclítico, o mesmo que en italiano e catalán, mais non en francés ou sardo. Porén, en case a totalidade das linguas románicas o clítico vai detras do verbo co imperativo.

${ }^{4}$ Entendemos como tempo unha macrocategoría que abrangue o tempo propiamente dito, $o$ aspecto e o modo. É tamén ben certo que as devanditas categorías, concordancia de persoa e de tempo, non poden ser sempre perfectamente separábeis en termos morfolóxicas, como acontece con comprei e compro, onde a marca de pasado fronte á de presente forma unha amalgama. 


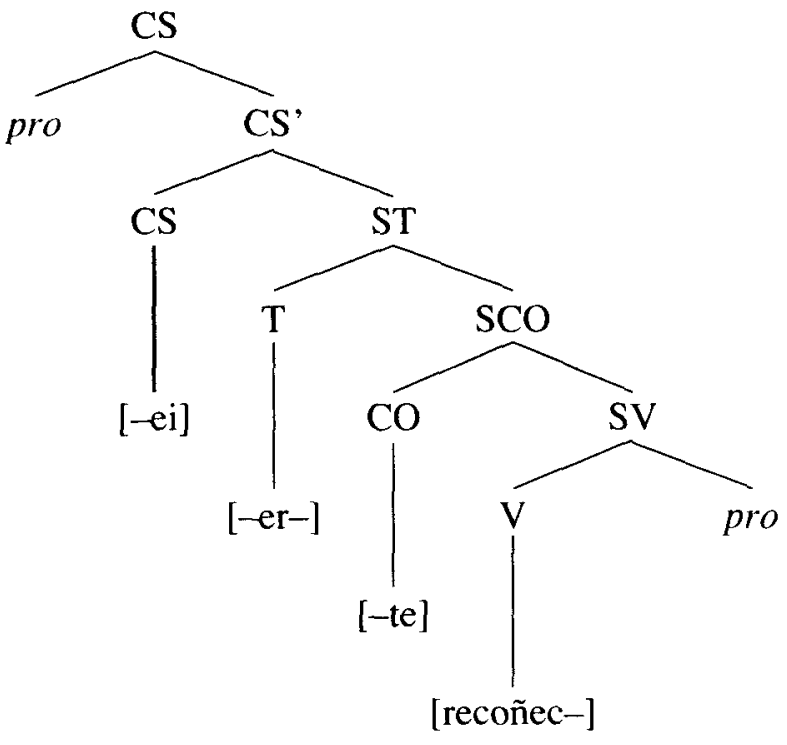

Loxicamente, o ascenso do verbo até a posición de CS é o que permite en galego, como no resto de linguas románicas, a fusión de todas as categorías verbais para formaren o verbo finito:

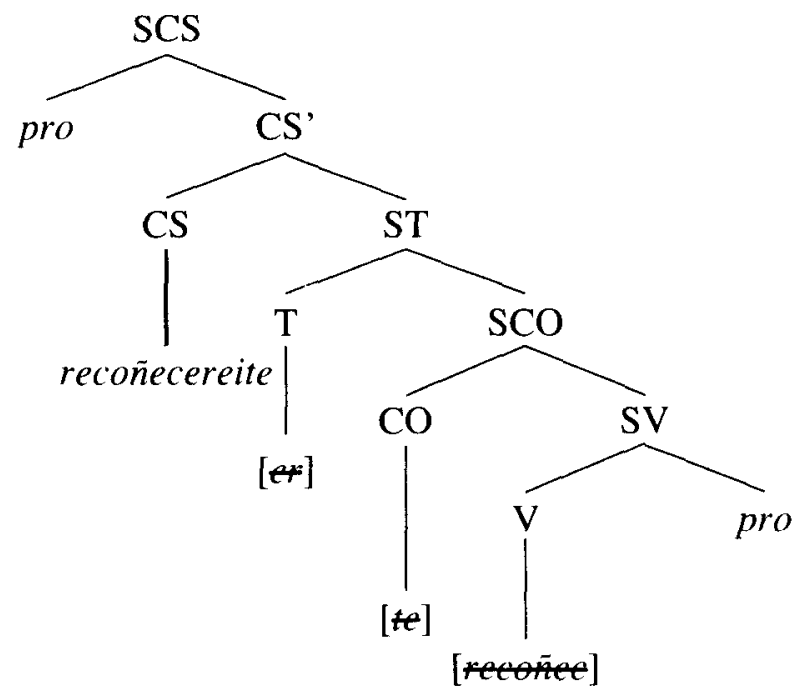

A representación da CS e do $\mathrm{T}$ como unha macrocategoría aínda superior, formada por morfemas ligados, tamén chamada ST (ou mesmo Flexión -F-), non inclúe nela a $\mathrm{CO}$, pois a presenza dos clíticos como morfemas flotantes non permite a súa representación. Deste modo, convén reescribir aínda a árbore anterior deste xeito: 


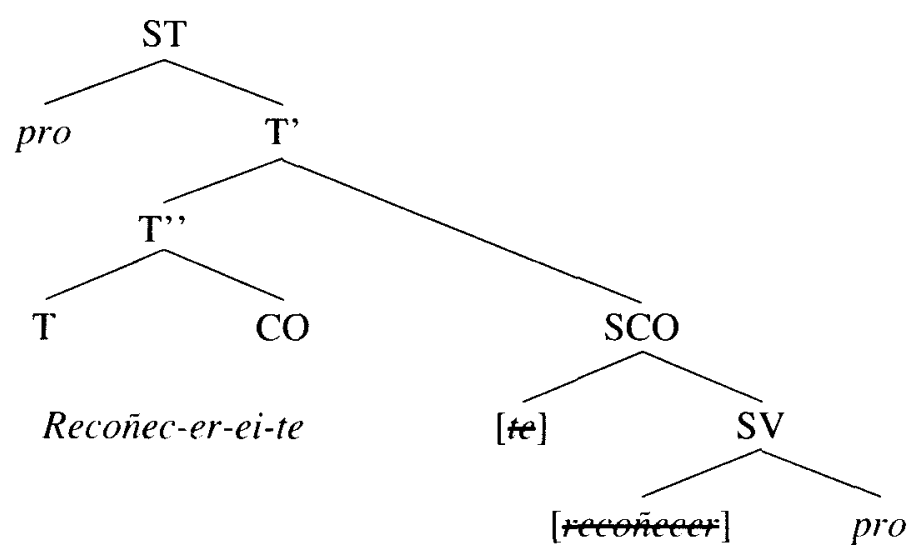

Despois da seguinte presentación, parece evidente que podemos considerar os clíticos galegos - e románicos en xeral— como unha categoría verbal, un xénero de morfemas, cunhas características especiais, que demos chamado morfemas flotantes pola súa capacidade de mudar de posición, e cuxa natureza é mixta entre os morfemas libres e os ligados. Unha proba máis disto é a mesóclise o tmese, propia aínda do portugués e que foi xacando normal en galego e castelán:

11. Ver-te-ei mais tarde

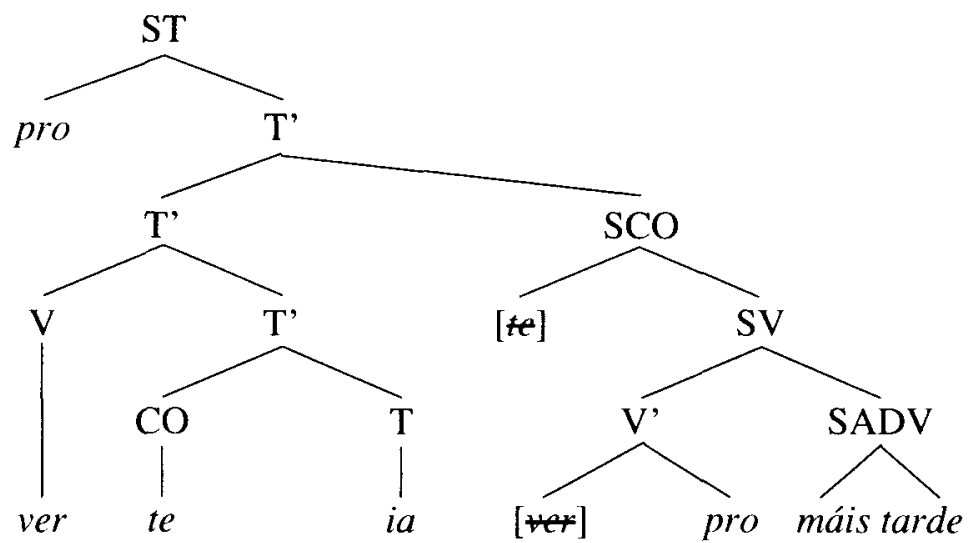

Proxectamos $T$ até tres veces, pois é a única maneira de entender cúmulos tan enormes.

\section{A organización do ST}

Como xa vimos anteriormente, os clíticos funden co verbo no ST, ascendendo desde o SCO. Ora ben, a característica máis senlleira do galego-portugués 
é que os clíticos poden ser enclíticos ou proclíticos a depender de certas regras perfectamente descritas na gramática tanto do galego como do portugués.

Partimos da base de que a énclise é a forma non marcada e de que a próclise é a marcada que se produce baixo certos contextos sintácticos, como a presenza da negación ou de determinados adverbios, cuxo emprazamento analizaremos a seguir.

En primeiro lugar, a negación é un dos elementos que provoca a próclise. En termos xerativistas, isto explícase por ser o sintagma negativo (SNEG) un sintagma forte que atrae o clítico á posición dianteira.

12. Non o sei.

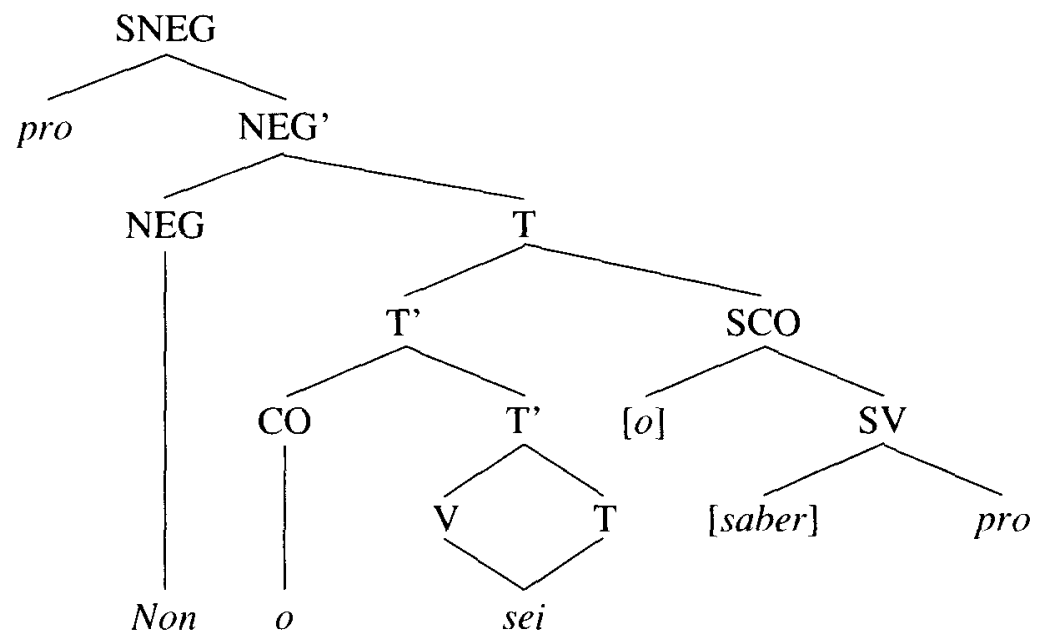

Idéntico caso ao da negación é da complementarización, cando un complementador (núcleo dun SC) localizado no inicio da cláusula atrae igualmente o clítico para a énclise, polo que debe ser considerado igualmente un sintagma forte.

13. [Dixo] que nos vira.

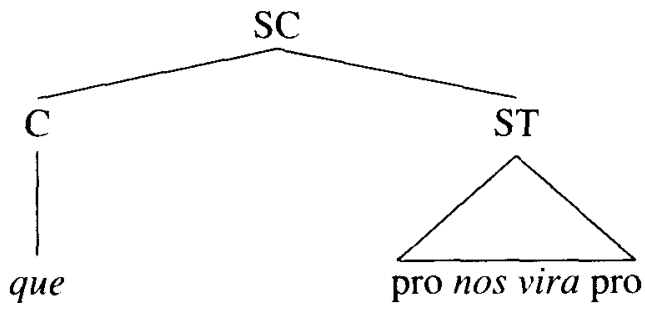

Tamén existen outros dous sintagmas fortes que arrastran o clítico á énclise. Trátase do Sintagma Interrogativo (SINT) e do Sintagma Focal (SFOC). Estas 
dúas categorías son desenvolvidas a partir da presenza do SC en cláusulas principais, cando hai presenza dun elemento que se sitúa alén do ST:

\section{Que me trouxeches pro [\#] [ de recordo?}

15. O ceo pro che compraría [ $] !^{5}$

Un caso ben distinto é o de certos adverbios que provocan a énclise, mais que non funcionan como operadores. Máis ben ao contrario, o seu comportamento aseméllase ao da negación, xa que se trata de sintagmas funcionais, de xeito que estes adverbios non son especificadores localizados en certo tipo de sintagmas nas partes superiores da árbore sintáctica. Teñen que ser, forzosamente, núcleos.

Referímonos a certos adverbios que aparecen nestes exemplos e que, en todos os casos, como xa ficou dito, provocan a énclise:

\section{Sempre me dixo a verdade \\ 17. Xa me chamará \\ 18. Tamén cho pedín \\ 19. Nunca as contei \\ 20. Tampouco o esperabamos de $t i$}

En ningún dos casos anteriores trátase dun sintagma tópico, que é feble, pois este non atrae o clítico para a posición inicial do cúmulo verbal:

\section{Onte merqueiche o libro}

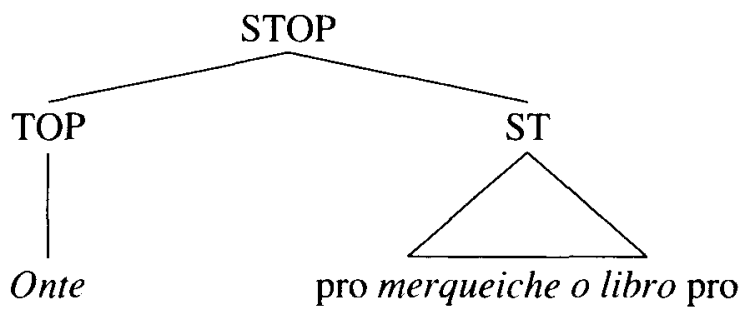

${ }^{5}$ É moi imporante neste caso distinguir dous tipos de focalización. A máis frecuente, aquela que simplemente move un operador á posición inicial, xeralmente un obxecto, non provoca a proclise:

- O pan merqueino [ ] na tenda

- Ao teu cuñado dixenlle [ que...

En troques, a focalización dupla, que coincide coa exclamación, si produce énclise.

- Todo o comiches!

A interpretación destes dous tipos de SFOC radica en que o primeiro ten un núcleo feble, que non atrae o clítico, e o segundo teno forte, e amais a propia exclamación é o seu núcleo. Pero é posíbel aventurar tamén que a focalización dun elemento temático sexa unha focalización feble, mentres que a focalización dun elemento non-temático si a produza, como acontece nos casos analizados nos exemplos (30) e seguintes. 
Por tanto, tales adverbios han ser interpretados como núcleos dun sintagma forte. Mais cal xénero de sintagma?

Se atendemos para os exemplos 17 e 18, atopámonos perante un SNEG, onde nunca, é especificador dun SNEG, estando non, o seu núcleo, implícito (véxase Frías-Conde, 2007), pois pode ser reformulado do seguinte xeito en galego, con dupla negación:

\section{Nunca non as contei}

23. Tampouco non o esperabamos

Os equivalentes portugueses:

24. Nunca $[\varnothing]$ as contei

25. Também não o esperávamos

E casteláns:

26. Nunca $[\emptyset]$ las conté

27. Tampoco $[\varnothing]$ lo esperábamos

E finalmente os cataláns, coa dupla negación obrigatoria:

28. Mai no les vaig comptar

29. Tampoc no l'esperàvem

Non é así, porén, en portugués ou español, linguas que non admiten a dupla negación, pero si en catalán.

Ora ben, como interpretar os exemplos con sempre? Para podermos achegarnos ao problema, convén utilizar a comparación, neste caso entre galego e inglés, malia seren linguas tan afastadas tipoloxicamente. A seguinte oración galega leva un elemento $s i$, que funciona dun xeito semellante ao devandito sempre. É de manual que a tradución deste adverbio equivale en inglés ao verbo do usado enfaticamente, sendo, xa que logo, o núcleo dun SFOC.

30. Eu si o vin

31. I did see it

- Neste exemplo apréciase perfectamente como a estrutura do tampouco galego é unha forma fusionada equivalente ao também não portugués, cuxa estrutura é: $\left[_{\mathrm{SNEG}}\right.$ também $\left[_{\mathrm{NEG}}\right.$ não]] 


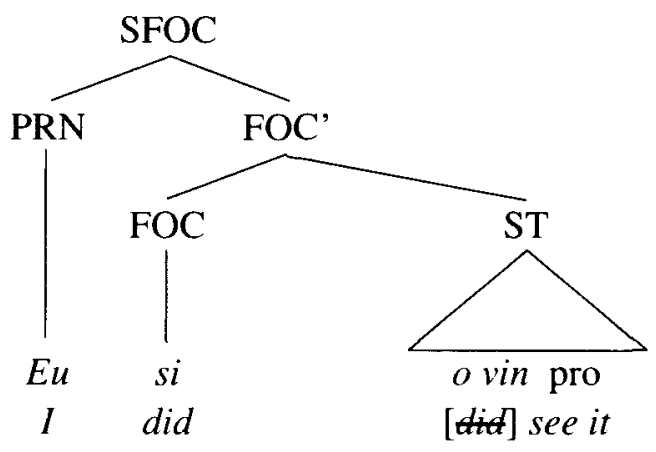

Non acontece o mesmo con outros adverbios como certamente, realmente, que non poden ser interpretados como núcleos:

\section{Eu certamente seino}

\section{Eu realmente seino}

Ora ben, se optamos por unha forma composta, é dicir, certamente que (pero non *realmente que), teriamos novamente un SFOC, que ten como núcleo que e como especificador certamente): $\left[_{\mathrm{SFOC}}\right.$ certamente $\left.\left[_{\mathrm{FOC}} q u e\right]\right]$.

Nestes casos podemos interpretar que se trata de núcleos de sintagmas tópico ou ben de operadores do ST, un duplo especificador que vén arreo do suxeito.

Réstanos, non obstante, interpretar cal é a natureza do sintagma que alberga $x a$. Cando ocupa unha proposición pre-verbal hai indicios para pensar que se trate tamén do núcleo dun sintagma focal, como acontecía con si ou sempre.

\section{Conclusións}

Ao longo destas páxinas, probamos facer un percorrido da natureza dos clíticos en galego atendendo a un achegamento xerativista. Demostramos que os clíticos teñen unha natura diferente dos pronomes persoais obxecto nas linguas románicas e que cumpren un papel de marcadores de funcións como morfemas verbais. Pero a súa consideración de morfemas verbais presenta o problema da súa natureza morfolóxica, porque non se adecúan á clasificación tradicional de morfemas libres e ligados. Xa que logo, propomos para eles a denominación de morfemas flotantes, que vale para todo o conxunto das linguas románicas.

Alén diso, describimos a énclise e próclise dentro da árbore sintáctica aplicada só ás formas simples do verbo. Partindo da base de a énclise ser a forma non marcada, os casos de próclise explícanse como atracción á posición pre-verbal do clítico por existir un sintagma forte que produce a devandita atracción, nomeadamente un SC, un SINT ou un SFOC. 


\section{BIBLIOGRAFÍA}

Figueiredo Silva, M. C. (1994): «Clíticos em galego: uma discussão dentro do quadro da teoria de regência e vinculação", En Actas do XIX Congreso Internacional de Lingüistica e Filoloxía Románicas. 267-275

FRÍAS-CONDE, F. X. (2003): «O comportamento sintáctico dos clíticos nas linguas románicas». En Interlinguistica 14, 383-398.

FRÍAs-CONDE, F. X. (2006): «La voix moyenne dans les langues romanes». En Revista de Filología Románica 23, 215-228.

FRÍAS-CONDE, F. X. (2007): «As construções negativas nas línguas iberorromânicas». En De Lingea Aragonensi, 2. SLA: Graus.

Martins, A. M. (1994): Clíticos na História do Português, vols. I-II. Lisboa, Faculdade de Letras da Universidade de Lisboa (dissertação de doutoramento).

Chomsky, N. (1995): The Minimalist Program. Cambridge, Mass, MIT Press.

RAdFord, A. (1997): Syntactic Theory and the Structure of English. A Minimalist Approach. Cambridge, Cambridge University Press.

Paiva Raposo, E. (1992): Teoria da Gramática. A Faculdade da Linguagem. Caminho: Lisboa. 